\title{
Rhythm Puzzle
}

\section{A Patient with Dizziness}

\section{A. Erol-Yilmaz • S. Westra • J. L. R. M. Smeets}

Published online: 1 February 2011

(C) The Author(s) 2011. This article is published with open access at SpringerLink.com

A 78-year-old man presents with dizziness for 3 days. This lasts for $30 \mathrm{~s}$ to $1 \mathrm{~min}$; he does not feel palpitations and has no other cardiac symptoms.

Nine years ago, he was analysed for chest pain; exercise testing and echocardiography were normal. His further medical history reveals depression and hemi-colectomy because of colon carcinoma. Current medication consists of aspirin, lisinopril, simvastatin, lithium carbonate, nortrilen, pantozol, alprazolam and movicolon.

Physical examination revealed a slow regular pulse of 40 beats/min with a blood pressure of $110 / 60 \mathrm{mmHg}$, and investigation of heart and lungs was within normal limits.
The ECG on admission is shown in Fig. 1. Laboratory examination showed a normal blood level of lithium and nortrilen. The echocardiography showed normal left ventricular function with a mild aortic stenosis.

What is your interpretation of the ECG?

Answer

You will find the answer elsewhere in this issue.

Open Access This article is distributed under the terms of the Creative Commons Attribution Noncommercial License which permits any noncommercial use, distribution, and reproduction in any medium, provided the original author(s) and source are credited.

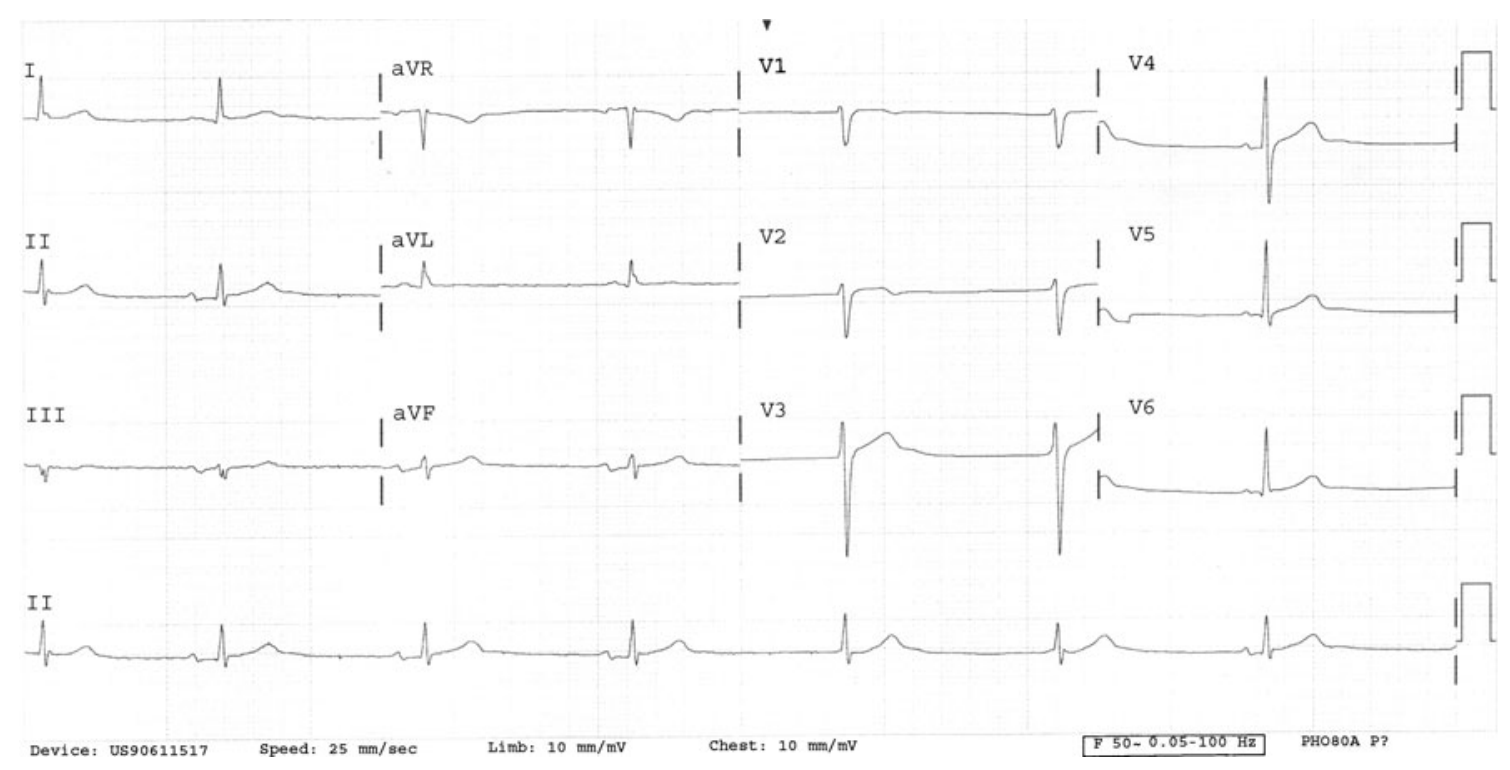

Fig. 1 ECG on admission $(25 \mathrm{~mm} / \mathrm{s}, 10 \mathrm{~mm} / \mathrm{mV})$

A. Erol-Yilmaz $(\bowtie) \cdot$ S. Westra $\cdot$ J. L. R. M. Smeets Department of Cardiology,

Radboud University Nijmegen Medical Centre, PO Box 9101, 6500 HB, Nijmegen, the Netherlands e-mail: erolyilmaz@live.nl

\section{Reference}

1. Levy MN, Zieske H. Mechanism of synchronization in isorhythmic dissociation. Circ Res. 1970;27:429-43. 